Política y Sociedad

ISSN: 1130-8001

ISSN-e: $1988-3129$

\title{
Cambio social y cambio artístico: autonomía de la esfera artística e influencia de la estructura en la sociología de las artes
}

\author{
Joaquim Rius-Ulldemolins ${ }^{1}$
}

Recibido: 17-08-2018 / Aceptado: 02-09-2019

Resumen. La interpretación de la influencia del cambio social en el cambio artístico ha sido desde el inicio de la sociología una cuestión controvertida. Así, para los autores clásicos de la sociología, el arte constituía un desafío a sus teorías. Sus aportaciones teóricas constituyen contribuciones valiosas, son importantes para desarrollar una perspectiva sociológica del cambio artístico. Sin embargo, la interpretación heterónoma de lo artístico respecto a lo social, especialmente por la perspectiva postmarxista o neodurkhemiana, impone severos límites al análisis del cambio artístico, que solo será superado a partir de la conceptualización weberiana del arte como esfera social autónoma. A partir de esta base, se analizarán tres corrientes de la sociología del arte (estructuralista, interaccionista e institucionalista), que intentan desencriptar la black box que representa la influencia social en la creación artística a partir de una perspectiva mesosociológica. No obstante, el surgimiento de las orientaciones posmodernas representa un retorno estimulante pero confuso del nivel de análisis macro que vuelve a poner en tela de juicio el debate sobre autonomía y la heteronomía del arte. El análisis crítico de la aportación de cada corriente y perspectiva de la sociología del arte sobre la autonomía y la influencia de la estructura será el objeto de este artículo.

Palabras clave: cambio social; cambio artístico; teoría sociológica; modernidad, posmodernidad, sociología de las artes.

\section{[en] Social Change and Artistic Change on Autonomy of the Artistic Sphere Structure Influence in Sociology of Arts}

\begin{abstract}
The interpretation of the influence of social change on artistic change has been a controversial issue since the beginning of sociology. In spite of the challenging status of the arts to sociological theory their contributions have been important to develop a social sociological perspective of art change. However, its heteronomous interpretation of the artistic with respect to the social, especially by the post-Marxist or neodurkhemian perspective, imposes severe limits on the analysis of artistic change, which will only be overcome from the Weberian conceptualization of art as an autonomous social sphere. From this base, three currents of the sociology of art are analysed (structuralist, interactionist and institutionalist) which attempt to decrypt the black box that represents the social influence in the artistic creation in a more meso-sociological way of interpretation. However, the emergence of the postmodern orientations represents a provocative but confusing return of macro level that puts into question the art's autonomy and heteronomy debate and, in this case, the determination of the structure in the interpretation of artistic change. The critical analysis of the
\end{abstract}

Universitat de València (España).

E-mail: joaquim.rius@uv.es 
contribution of each current and perspective of the sociology of art on the autonomy and influence of the structure will be the object of this article.

Keywords: social change; artistic change; sociological theory; modernity; postmodernity; sociology of arts.

Cómo citar: Rius-Ulldemolins, J. (2020): “Cambio social y cambio artístico: autonomía de la esfera artística e influencia de la estructura en la sociología de las artes", Política y Sociedad, 57(1), pp. 217-239.

Sumario. 1. Introducción. 2. Teoría sociológica clásica y el tipo de explicación del cambio artístico. 3. La sociología de las artes y el cambio social y artístico: el debate sobre la influencia de la estructura y la capacidad de la agencia. 4. La perspectiva posmoderna del cambio artístico centrada en el espacio: el retorno de la perspectiva macro y sus sobreinterpretaciones. 5. Comentarios finales. 6. Bibliografía.

\section{Introducción}

¿Por qué las artes cambian? ¿Por qué cambian más rápido en unos periodos históricos que en otros? ¿Los cambios artísticos pueden ser interpretados como producto de los cambios sociales? ¿Cuáles son los elementos que lo impulsan y quiénes los protagonistas del cambio artístico? Tomadas estas preguntas en su raíz conceptual, el cambio social, apuntan a una problemática clásica y central de la sociología: los factores y agentes del cambio. Por otra parte, el debate sobre el cambio social aplicada al cambio del mundo del arte, aunque tardío en relación a otras esferas sociales, se ha convertido en un objeto crecientemente central en los debates de la teoría sociológica. Una centralidad que se ha acentuado al ser la cultura una esfera cada vez más significativa para interpretar las sociedades avanzadas (Boltanski y Chiapello, 2002; Menger, 2009; Bourdieu, 2013).

Es cierto que la cuestión del estatus del arte en el análisis de la modernización generó una notable incomodidad de la sociología clásica (con la excepción en cierta medida de Simmel) por la dificultad de interpretar su dinámica de cambio con los parámetros de sus teorías y conceptos (Menger, 1992) ${ }^{2}$. Sin embargo, el desafío de interpretar la influencia que tiene el contexto social en el arte, para algunos autores revela las dificultades de las ciencias sociales para articular niveles de análisis y para la correcta concepción de estructura y agencia, lo que constituye asimismo un acicate para el desarrollo de nuevas perspectivas sociológicas (Heinich, 1998). Por ello son necesarias nuevas perspectivas que rechacen el determinismo social y sean capaces de concebir los condicionantes de la estructura

\footnotetext{
2 Podría ser objeto de debate si en la etapa de la fundación de la sociología el arte fue ignorado como objeto de estudio. En todo caso, podemos afirmar que existe un consenso en que, para algunos autores como Marx, Durkheim o Weber, las artes ocuparían un lugar marginal porque pondrían en evidencia los límites o las dificultades de sus teorías para describir las prácticas y los valores artísticos (Menger, 1992). Para la teoría durkhemiana, es difícil entender que una producción individual puede ser adoptada como símbolo colectivo. Para la teoría marxista es un contrasentido explicar, por un lado, la singularidad de la producción de las obras de arte (que contradice la teoría del valor basada en el tiempo de trabajo) y al mismo tiempo la universalidad de su significado y placer estético. Finalmente, para Weber, las artes vendrían a significar la excepción a la racionalización y a la burocratización de la sociedad moderna. Aunque ciertamente, Weber explicaría esta singularidad a partir de la noción de carisma, sin embargo, no dejaría de ser una caja negra dentro de su teoría (Menger, 2009).
} 
a partir de herramientas heurísticas aptas para su utilización empírica, sin por ello caer en la analogía orgánica del reflejo u otros determinismos que anulan la capacidad de agencia (Heinich, 1998; Passeron, 2011).

Pero ¿qué es el cambio artístico desde una perspectiva sociológica? Es evidente que no solo estamos refiriéndonos al cambio estético, un análisis propio de la historia del arte o, en cierta medida, de la filosofía, en cuyo caso estaríamos centrándonos en el tipo de análisis interno propio de estas disciplinas, referido a obras y autores o, de forma más general, a estilos y grupos o escuelas artísticas. En el desarrollo del análisis sociológico, este ha debido superar la etapa que Nathalie Heinich califica de "estética sociológica" y la "historia social del arte", que ve en el arte un reflejo de la sociedad o bien se limita a algunos aspectos de la creación, pero que es incapaz de captar el conjunto del mundo del arte (Heinich, 2001). Por ello, estas orientaciones no constituirían un tipo de análisis que pudiéramos calificar propiamente de sociológico, el cual, como observa Zolberg, siempre implica una combinación con otros elementos externos (Zolberg, 2016). La cuestión desde un punto de vista sociológico es cómo ha evolucionado la concepción de la relación entre las dos dimensiones, sociedad y arte, y los factores de causalidad que se le ha atribuido.

Por lo tanto, el objeto de este artículo será analizar cómo ha evolucionado la preponderancia de los factores o los agentes del cambio social en el sentido de cambio significativo en una escala meso o macro, y no solo como un mero reajuste micro o mesosocial (Nisbet y Kuhn, 1993). A lo largo del artículo analizaremos los nexos explicativos entre el cambio artístico y el cambio social. Empezaremos con las interpretaciones de causalidad orgánica y eficiente entre los dos fenómenos (y con ello la idea del arte como manifestación de la civilización o reflejo de la estructura social), hasta llegar a las lecturas contemporánea de la aportación de Max Weber en su conceptualización de la modernidad como un proceso de separación de las esferas sociales (Weber, 1944). Ciertamente, con la incorporación de la idea de la autonomía, encontraremos los desarrollos más fructíferos de la sociología del arte. Dentro de esta perspectiva se han construido líneas de investigación y trabajos sobre el cambio artístico con un énfasis más determinista o probabilístico, con un enfoque más unicausal o multicausal o que establecen una mayor heteronomía o autonomía de autorregulación de la esfera artística (Bourdieu, 2002).

El análisis de los diferentes desarrollos y su aportación a la comprensión de los factores sociales que impulsan el cambio artístico será el núcleo de este artículo estructurado en tres partes. 1) Iniciaremos el artículo con una exploración de la etapa de la historia social del arte que, hasta los años sesenta del siglo XX, hegemonizó las explicaciones de la relación entre cambio social y cambio cultural. Así, no será hasta el surgimiento de los nuevos paradigmas de la sociología del arte y de los cultural studies cuando superarán sus limitaciones interpretativas y, que debido a su mecanicismo, abandonarán por ello los grandes esquemas interpretativos anteriores (el marco social de la etapa histórica y la estructura de clases como factor interpretativo) e introducirán nuevas variables en el análisis. En el caso de los cultural studies, estos nuevos factores serán la etnicidad, el elemento generacional, los medios de comunicación o la creatividad de los milieux populares entre otros (Hall, 1992). 2) En segundo lugar, 
analizaremos las aportaciones de la sociología de las artes y su desarrollo de teorías y conceptos interpretativos de alcance medio para descifrar la black box de la relación entre el cambio en el mundo del arte y cambio social. En este apartado recogeremos las significativas aportaciones de esta corriente desarrollada a partir de los años setenta y sus diversas perspectivas: a) la perspectiva estructuralista encabezada por la teoría de los campos artísticos de Pierre Bourdieu, b) la perspectiva interaccionista de la sociología de los mundos del arte de Becker y la sociología de los mercados y las profesiones artísticas de Raymonde Moulin (1983, 1997) y Pierre-Michel Menger (2009) y, finalmente, c) la perspectiva institucionalista de la producción de la cultura fundada por Richard Peterson (Peterson, 1982; Peterson y Anand, 2004). En estas tres perspectivas distinguiremos los diferentes conceptos y herramientas heurísticas utilizados y, asimismo, estudiaremos la cuestión de la preponderancia entre factores explicativos y su consideración de la relación entre esferas sociales y la autonomía relativa del cambio en el mundo artístico. 3) En tercer lugar, terminaremos con el análisis del cambio abordando el debate clásico entre cambio social, niveles de análisis (el nivel macro de sistemas y macroestructuras, el nivel meso de sistemas organizativos y normativos y el nivel micro de grupos e individuos, roles y trayectorias) para debatir en el ámbito artístico la importancia que da cada corriente teórica al factor estructural o agencial.

\section{Teoría sociológica clásica y el tipo de explicación del cambio artístico}

\subsection{Cambio social y cambio artístico: la visión evolucionista y circular del cambio artístico y social}

Intentar definir cambio artístico a priori supondría entrar en el debate de qué es el arte, y ello nos conduciría a un cul de sac interpretativo. Esto se debe a que la deconstrucción y problematización del concepto de arte ha sido precisamente uno de los objetivos del mundo artístico del siglo XX (Zolberg, 2016). Por ello, aunque el cambio en las formas y los soportes artísticos forma parte del objeto de estudio, no se deben tomar en cuenta solamente los factores internos, sino también los factores externos, es decir, la configuración institucional del mundo artístico, sus roles y funciones o la valoración social que se hace de este mundo y sus productos. Al contrario, el cambio de estos factores externos contextuales, profesionales e institucionales del mundo del arte será, por lo tanto, uno de los terrenos privilegiados del análisis sociológico.

Definido el ámbito de lo que entendemos por cambio artístico, empezaremos por constatar que las primeras visiones desde las ciencias sociales interpretaron este cambio a partir de una concepción integrada del arte y la sociedad. Así, esta concepción estuvo muy influenciada por el evolucionismo sociológico, que concebirá la idea del cambio cultural como una parte inseparable y orgánica del cambio social. De hecho, el cambio artístico será utilizado como una forma de medir y demostrar el advancement social (Granovetter, 1979). De esta forma, en Francia, en la última mitad del siglo XVII, se produce una famosa querella entre 
antiguos y modernos. Hubo un debate intelectual entre los que, por un lado, creían que nada de lo que se había escrito o realizado intelectualmente en los tiempos modernos igualaba en calidad a las obras de la antigüedad clásica, como Boileau o Swift, y, por otro lado, los partidarios de los modernos como Fontenelle y Perrault, que sostenían lo contrario: la superioridad de los creadores contemporáneos respecto a los antiguos. Estos últimos partían de la invariabilidad de las leyes de la naturaleza cartesiana: el axioma de que si la mente tiene las mismas condiciones y además tiene más experiencia, necesariamente se debe producir un avance intelectual y artístico. Cabe señalar que estos autores utilizaban la analogía de la vida humana, pero se saltaban la etapa de la vejez y decrepitud, tal como señala Georges Sorel, que por ello consideraba la idea de progreso como un engaño burgués (Sorel, 1947). En efecto, estos desarrollaban un argumento circular, ya que en primer lugar afirmaban que Moliere era superior a Esquilo y, por lo tanto, según ellos esta evolución positiva demostraba que había progreso. Y para sustentar la idea anterior utilizaban el argumento de que la superioridad provenía del progreso de la humanidad, por lo que se trataba de un argumento circular y de una falacia argumentativa. Sin embargo, la concepción modernista prevaleció y de facto fue una idea predominante: la novedad artística era la prueba de progreso, y ello duró hasta la crisis de la modernidad, a finales del siglo XIX (Rosenberg, 1959).

Ciertamente, podemos encontrar una visión integrada del cambio social y el cambio artístico que en principio es contraria al credo evolucionista, pero que en relación al cambio cultural comparte ciertas características: las teorías circulares de la historia y el cambio social. Estas teorías difieren en sus visiones de las etapas históricas y sus lógicas, pero vienen a compartir diversos elementos: 1) En primer lugar, los elementos culturales forman parte esencial de cada civilización, al igual que los desarrollos sociotécnicos, y conforman un itinerario propio e independiente de cada civilización. 2) En segundo lugar, según plantean algunos conocidos defensores de esta visión del desarrollo social y cultural como Spengler, se pueden observar periodos de emergencia, plenitud y decadencia en los que las artes son un indicador de cada estadio. Así, tanto Spengler (1966[1918]) como Pitrim Sorokin (1966) concebirán el arte moderno y su autonomía estética como un indicador de la decadencia de la civilización occidental. 3) En tercer lugar, la única autonomía que reconoce a la cultura respecto a la civilización es la idea de que la cultura es desarrollada por las élites y que, por lo tanto, esta es un indicador de la "calidad" de estas, en una aproximación como vemos muy sesgada y valorativa. Desde Ibn Jaldun (Çaksu Ali, 2017) hasta Sorokin (1937), pasando por Toynbee (1970), la élite se legitima y representa un élan creativo que puede agotarse o bien corromperse por una adaptación a los periodos de abundancia y desarrollo pacífico en el que el arte se convierte en símbolo del hedonismo y la relajación moral (Pareto y Aron, 1968).

\subsection{El reflejo y la sombra: la historia social del arte $y$ sus defectos interpretativos}

Una de las concepciones desarrolladas largamente en el análisis del cambio artístico ha sido la historia social del arte, en la que el estudio interno del arte se 
centra en el artista y sus contextos sociales, aunque también se amplía a los grupos y escuelas artísticas y sus configuraciones institucionales (Cf. Furió, 2000). A esta orientación se le añadió paralelamente el estudio social del arte surgido de posiciones marxistas. Según uno de sus principales valedores, Raymond Williams, se debe partir de una evaluación de las condiciones sociales del arte. Según esta perspectiva, se hace un énfasis en los elementos históricos y los elementos psicológicos, que conducen a definir grandes periodos en la historia del arte (Williams, 1994) ${ }^{3}$. Así, en esta etapa se establece que las obras de arte constituyen un reflejo de un periodo social. Este es el análisis de Lukács, que relaciona la emergencia de la burguesía comercial en el siglo XVIII con el auge de la novela realista (Lukács, 1975).

Sin embargo, el punto débil de esta tendencia radica en la poca capacidad para explicar la variabilidad y el cambio en las formas artísticas, partiendo de una antropología universalista o de grandes periodos históricos (Zolberg, 2016). Otro de los límites de la interpretación social del arte es el determinismo y su sesgo epistemológico. Los análisis se centran en el estudio de aquellos sectores artísticos y géneros en los que se pueden ver reflejadas con mayor claridad las condiciones sociales, como la novela realista. Pero ¿cómo analizar desde esta perspectiva la poesía, la música atonal o el arte abstracto? Así, esta interpretación sesgada suele exagerar la homogeneidad cultural de las sociedades, obviando la existencia de subculturas, y suele también caer en el anacronismo de la sincronización de los relojes, es decir, forzar la coincidencia de la historia cultural con la historia social. Un ejemplo de ello es la interpretación sincrónica de la revolución impresionista con la revolución burguesa, perspectiva que se ha comprobado del todo forzada en su correlación temporal y causal, puesto que el impresionismo como movimiento artístico se explica por el cambio social de la estructura artística (el paso del sistema académico al de mercado del arte), y no por cambios macro en la esfera política (White y White, 1991). Por último, con la irrupción del estalinismo en el ámbito intelectual a partir de los años treinta, esta perspectiva además deriva en una legitimación de un "arte social", o peor, de un "arte de partido", y se sustancia en una doctrina artística conocida como "realismo socialista". La consecuencia de esta perspectiva será la exclusión como "artes burguesas" o ejercicios de "formalismo estético burgués" de las disciplinas o las corrientes que se alejan y de los análisis que preconizan en cierto momento la autonomía en la interpretación del arte respecto del contexto social.

Otra escuela que podemos encuadrar dentro de la historia social del arte es la derivada del estructural funcionalismo. Esta parte en su perspectiva de un menor determinismo sociohistórico y tecnológico, aunque no está exenta de ello. Uno de sus autores más destacados es Vytautas Kavolis, que con su History on Art's Side: Social Dynamics in Artistic Efflorescences parte de la

\footnotetext{
No es el objetivo de este artículo caracterizar la concepción marxista de la cultura, cuestión desarrollada por otros autores como el mismo Raymond Williams (1997). Sin embargo, como hemos señalado anteriormente y este mismo autor reconoce, la relación entre contexto social y arte —o en términos de la teoría marxista, entre la infraestructura y la superestructura - dista de ser clara y mecánica (Williams, 1997). En palabras del propio Marx: "En lo que respecta al arte, es bien conocido que algunas de sus cimas no se corresponden en absoluto con el desarrollo general de la sociedad; y, por lo tanto, tampoco se corresponden con la superestructura material, con el esqueleto, por así decirlo, de su organización. Marx, citado por Williams (Williams, 1997: 97).
} 
idea de fase-ciclo en la que se producen efforescences de la creatividad en cantidad y calidad. En estos ciclos se producen cuatro fases: 1) una inicial perturbación del equilibrio, 2) una búsqueda de soluciones que estimula la creatividad, 3) una fase de reintegración que pone en común lo nuevo y lo viejo $y$, finalmente, 4) una fase final de reducción de la tensión. Mientras la primera y la tercera estimulan una intensa creatividad, la segunda fase dirige las fuerzas más allá de la esfera artística, y la cuarta diluye el élan creativo por ausencia de tensión. Esta corriente se apoya en la idea parsoniana del cambio como diferenciación y especialización. Así, el arte es indicador de desarrollo, aunque no en el sentido marxista de desarrollo de las fuerzas productivas, sino que se convierte en un elemento modulado por la percepción emocional de la economía (Kavolis, 1965). Por otra parte, según Kavolis, son la coincidencia de un momento de ruptura, el intento de generar cohesión social y la disponibilidad de recursos los que pueden generar un momento de florecimiento de las artes (Kavolis, 1966). Ciertamente, la posibilidad de poder correlacionar grandes magnitudes microsociológicas con cambios a nivel artístico decaerá con la crisis de la "gran sociología" y de los intentos comparativos, criticados pero añorados (Gouldner y Míguez, 1979, Tilly, 1991). Es una perspectiva que se eclipsará con la llegada de la sociología del arte contemporánea, y que solamente reaparecerá en los años noventa con la llegada de la sociología posmoderna y su cultural turn en la interpretación del cambio social (Ritzer, 1997). Sin embargo, este retorno vendrá muy influenciado por la sociología neoweberiana y su concepción de las esferas sociales relativamente autónomas propias de la modernidad.

\subsection{Max Weber, la diferenciación de esferas sociales y la autonomía del arte}

Max Weber ha influido en la mayoría de las corrientes de la teoría sociológica actual (Collins, 1987), y ciertamente puede considerarse como unos de los padres de la sociología de las artes presente. Su aportación es una crítica a la idea integrada de la evolución del arte y la sociedad, de la concepción del reflejo, así como de las lecturas internalistas de la evolución del pensamiento y del arte. En primer lugar, Weber rechaza a la vez la concepción materialista e idealista de la historia, así como la idea de la separación entre ciencias naturales y ciencias sociales, aunque reconoce una especificidad a las ciencias sociales. A esta última, que consiste en la capacidad de comprensión de los fenómenos sociales respecto a los naturales, se la caracteriza como verstehen: la capacidad de comprensión de los actos sociales, la interacción y la historia de la humanidad a través de esta herramienta hermenéutica. Por lo tanto, Weber cree que la sociología no debe buscar leyes universales o una causalidad única y necesaria: la sociología busca formular conceptos tipo y generalizar las regularidades y los procesos empíricos. Esto la distingue de la historia que está orientada al análisis causal y a la explicación de las acciones individuales, estructuras y personalidades que poseen un significado cultural (Weber, 1944: 19).

De este modo, una de sus mayores aportaciones al análisis del cambio social y cultural es su teoría sobre el proceso de racionalización. Un proceso que es el vector principal de cambio de la modernidad, y que implica sistematización, 
normativización, delimitación competencial, etc. Una consecuencia fundamental de ello es la distinción entre esferas: esfera económica, esfera política, esfera artística, etc. De este modo, en una sociedad poco racionalizada, las esferas de la política, la religión, la ciencia o el arte están poco delimitadas y se mezclan fácilmente, como, por ejemplo, la figura del bardo celta, que mezcla funciones simbólicas, políticas y religiosas (Williams, 1994). Por el contrario, en las sociedades modernas, cada una de estas áreas está relativamente desligada y aspira a fijar sus propios criterios diferenciados, a veces en oposición a las normas de otras esferas (como la lógica de las artes, que se opone a aquellas de la política, las normas científicas e incluso a las reglas de lo considerado como bello o de buen gusto (Bourdieu, 2002)) Así, eigengesetzlichkeit es el término alemán para señalar esta lógica intrínseca de las esferas sociales. Una consecuencia de la eigengesetzlichkeit es la inevitabilidad de los conflictos radicales entre esferas de valor; es la tendencia de las esferas de valor para convertirse en dominios cada vez más autónomos de pensamiento, acción y pasión (Oakes, 2003). En este sentido, cada esfera de valor sigue su propia ley, una lógica inmanente que la distingue de otras esferas y agudiza los conflictos entre ellas. Aunque eigengesetzlichkeit es una propiedad del valor de las esferas y un artefacto de la cultura, muestra de este modo su concepción de lo que significa ser humano: trascender todas las contingencias de la cultura y la historia. Con este concepto, Weber indica la necesidad de un estudio individualizado de cada fenómeno social, político y cultural. Asimismo, se dirige al corazón de la teoría marxista no para destruirla, sino para señalarla como insuficiente, al no poder reducirse el arte y lo cultural, en general, a lo económico (Giddens, 1994).

La generación de esferas presupone una institucionalización interna, con el surgimiento de un grupo social especializado que la estructura y la regula. En este espacio social: 1) Se desarrolla uno al grado de diferenciación entre papeles y esferas institucionales. Ahí estos nuevos agentes no tienen solo un papel delimitado y pasivo, sino que sus descripciones de los nuevos campos se desarrollan como formas de definición de lo que debe ser el campo, al delimitar y expandir los ámbitos de actuación. Un ejemplo de ello se da en la nueva burocracia estatal, en la génesis del campo burocrático a finales del XVIII y principios del XIX (Bourdieu, 1997). En este marco surgirán también las primeras estructuras artísticas, como el sistema académico, que será decisivo en la autonomización del arte como esfera social (Heinich, 1983). 2) Los papeles no se desarrollan en función de los grupos primarios y particularistas, sino a partir de criterios que se basan en ciertos elementos universalistas, base del discurso abstracto y universalista del campo artístico (Casanova, 2001). 3) En estos nuevos campos, los grupos de los diferentes campos necesitan, para desarrollar sus objetivos, expertos y cooperar con otras actividades especializadas. Al mismo tiempo, hay una competencia entre varios grupos sobre el orden y la prioridad de los diversos objetivos y los recursos necesarios para conseguirlos (Eisenstadt, 1973). Será sobre esta base de la teoría weberiana de la autonomía de las esferas sociales y sus desarrollos contemporáneos que se asentará la sociología del arte contemporánea, y que hemos dividido en tres corrientes: la sociología del arte estructuralista, la sociología del arte interaccionista y la sociología del arte institucionalista. 


\section{La sociología de las artes y el cambio social y artístico: el debate sobre la influencia de la estructura y la capacidad de la agencia}

\subsection{La sociología del arte estructuralista: el campo artístico autónomo como marco del cambio}

Desde la segunda mitad del siglo XX, han surgido dos grandes corrientes en la sociología de la cultura moderna: la corriente estructuralista y la interaccionista. Por una parte, encontramos la corriente estructuralista, encabezada por Pierre Bourdieu, pero en la que participaron otros investigadores como Jean-Claude Passeron, Jean-Claude Chamboredon, Christophe Charle o, en sus inicios, Luc Boltanski (Pinto et al., 2004). Estos desarrollan nociones, como la de campo artístico, capital simbólico o illusio; conceptos todos ellos muy valiosos para la conceptualización y el análisis empírico de los sectores culturales. De este modo, desde la perspectiva estructuralista, el campo artístico se definirá por ser relativamente autónomo de la sociedad en general, y su dinámica de cambio estará condicionada por dos ejes estructuradores: el antagonismo que opone el arte comercial al arte de vanguardia, y un segundo eje que enfrenta las vanguardias consagradas a las vanguardias emergentes. En su interior los creadores y los intermediarios desarrollarán estrategias para conseguir conservar o subvertir las jerarquías artísticas a través de la acumulación del capital simbólico. Ciertamente, las tendencias dominantes o revolucionarias dentro del campo artístico irán ligadas a las posiciones objetivas dentro del campo social: los dominantes tienden a imponer posiciones conservadoras en lo estético y en lo político, y los vanguardistas a promover estrategias heterodoxas y subversivas en los dos ámbitos. Sin embargo, no podemos establecer una clasificación binaria entre campo artístico y campo político (dominantes-derecha y vanguardistas-izquierda), sino establecer alianzas con las diferentes clases o fracciones sociales, pero el cambio artístico no se interpretará de forma determinista por un cambio en la estructura social o un proceso histórico externo a este campo social (Sapiro, 2017) ${ }^{4}$.

A pesar de algunas interpretaciones superficiales, que le atribuyen un carácter reduccionista y determinista en la relación que establece entre esfera artística y la estructura social (Hennion, 2004), la interpretación del cambio artístico de la corriente estructuralista de la sociología del arte tiene dos vertientes. Por una parte, es verdad que la idea de la homología estructural entre espacio de los consumos y espacio de las clases y fracciones sociales es central en su análisis del consumo cultural, y puede ser sobreinterpretado de forma determinista y simplificar la

\footnotetext{
Por ejemplo, en La raison littéraire. Le champ littéraire français sous l'Occupation (1940-1944) enicontramos el estudio sobre la ocupación alemana de Francia durante la Segunda Guerra Mundial realizado por Gisèle Sapiro (1996) bajo la dirección de Bourdieu, se analiza cómo la situación creada por la voluntad de las autoridades culturales ocupantes en alianza con el sector de extrema derecha del campo literario francés provoca un intento, en gran medida frustrado, de toma del poder en la jerarquía literaria por parte de estos, para desplazar así a los antiguos escritores dominantes. Sin embargo, el estudio muestra los límites de una explicación heterónoma del cambio artístico. En primer lugar, el cambio viene motivado por factores intrínsecos al campo literario, por la competencia interna por el poder simbólico, y la motivación son las ambiciones literarias de los participantes en este cambio, de ahí el título de la obra: la razón literaria (que no solamente política) del cambio artístico. En segundo lugar, el trabajo muestra los límites de este cambio, el fracaso de la fracción ligada a la extrema derecha en conquistar el poder literario, a pesar de contar con poderosos aliados en las fuerzas ocupantes, las autoridades del Estado colaboracionista de Vichy y verse sometido buena parte del campo artístico a la represión, el exilio o la censura.
} 
cultura como un recurso para reforzar la desigualdad social en las sociedades avanzadas (Coulangeon y Duval, 2013). Sin embargo, por otra parte, en relación a su análisis de los artistas y los intermediarios culturales desarrollado desde los años setenta en su artículo seminal "Le marché des biens symboliques", su concepto de campo se basa principalmente en la idea de la autonomización y del surgimiento de una lógica propia del campo, un eigengesetzlichkeit en términos weberianos (Bourdieu, 1977). Esta concepción lo convierte en una esfera relativamente separada del campo social general e invierte algunas de sus lógicas, como la lógica económica capitalista del beneficio a corto plazo por las estrategias de acumulación de capital simbólico a largo plazo, un concepto desarrollado en "La production de la croyance" (Bourdieu, 1977). Ciertamente, en este último artículo insiste en la homología entre productores y consumidores (destacando así la relación entre las dos esferas), pero este tipo de análisis vuelve a matizarse en obras posteriores como Las reglas del arte (Bourdieu, 2002) o en el análisis publicado póstumamente sobre Manet. Une révolution symbolique (Bourdieu, 2013). De este modo, en sus trabajos sobre la teoría bourdiniana en relación al cambio establece que "Las relaciones de dependencia y de incrustramiento entre campos así como los alianzas tejidas con las fuerzas exteriores para afirmar su autonomía o, al contrario, reforzar su subordinación son, con las luchas internas, los principales factores de su evolución que no tienen nada de teleológico ni de lineal (Sapiro, 2013) ${ }^{5}$. Por lo tanto, no son los factores externos, sociales, políticos o de otra índole, sino las dinámicas internas, los antagonismos y alianzas de los agentes artísticos en relación a otros agentes los que producen el cambio. Por ejemplo, los artistas se alían con el Estado a través de las academias para marcar distancias con el dominio religioso y de la aristocracia hacia el campo artístico (Heinich, 1983; Heinich, 1990). Además, en una etapa posterior, los partidarios de un distanciamiento entre lógica social y artística ganan peso, e inician un largo proceso de búsqueda de la autonomía a través de la creación de un mercado y del rechazo de la intervención del Estado; un rechazo que continuará hasta los años cincuenta del siglo XX (Dubois, 1999; Menger, 2011).

Por otra parte, Pierre Bourdieu puede ser también considerado un sociólogo de la crisis y el cambio artístico. En particular sus trabajos al final de su vida, entre 1998 y 2000, acerca de Manet (Bourdieu, 2013) muestran un ejercicio de análisis de las revoluciones simbólicas. Tomado como caso paradigmático, al mismo nivel que Flaubert en el caso de la literatura que había estudiado en la obra anterior (Bourdieu, 2002), Manet constituye un agente de la transformación de nuestras categorías de percepción y apreciación. Esta provocará el paso de la estructuración del mundo del arte como cuerpo social a una estructuración como campo artístico, en una lucha contra la legitimidad del sistema académico - un conjunto de instituciones integradas y en último término garantizadas por el Estado- que comportará, según palabras de Bourdieu, la "bancarrota" del capital simbólico del academismo, sus pintores y sus pinturas (Bourdieu, 2013). De este modo, el cambio artístico supone un cambio estructural, que a su vez viene impulsado y genera un nuevo habitus: el habitus artístico. La ruptura del sistema académico

Traducción del francés: "Les rapports de dépendance et d'encastrement entre champs ainsi que les alliances nouées avec des forces extérieures pour affirmer leur autonomie ou au contraire renforcer leur subordination, sont, avec les luttes internes, les principaux facteurs de leur évolution, qui n'a rien de téléologique ni de linéaire" (Sapiro, 2013). 
constituye asimismo el hundimiento del monopolio al acceso y a los mecanismos de consagración, dirigido a la reproducción controlada del cuerpo y que impulsaba al conformismo y al conservadurismo entre los artistas y los aspirantes a entrar en la carrera artística. Así, podemos comparar el habitus del pintor académico al del homo academicus analizado por Bourdieu, del que resalta el conformismo entre los aspirantes a la entrada de la carrera académica (Bourdieu, 2008). Por el contrario, la constitución del campo artístico basado en la competencia entre vanguardias consagradas y vanguardias emergentes generará un habitus transgresor que, en alianza con otros creadores e intermediarios, intentará a través de la redefinición del objeto artístico, la acumulación de capital cultural y el cambio artístico que comporta un cambio en la jerarquía de los artistas y la captura del poder simbólico dentro del campo (Bourdieu, 1977; Bourdieu, 2002). Por lo tanto, el trabajo de Bourdieu, lejos de poder ser considerado determinista, con su noción de habitus intenta romper el dualismo estructura y agencia (Lizardo, 2004) ${ }^{6}$, atribuyendo al sujeto la capacidad de agencia, como es el caso de Manet, caracterizado como heresiarca (transgresor y creador de nuevos principios), es decir, capaz de cambiar la forma de crear y también de percibir el arte. Esta idea de las revoluciones simbólicas entronca aquí con la interpretación de Eisenstadt de la noción weberiana del carisma como fuerza no solamente destructiva, sino capaz de generar nuevas instituciones (Eisenstadt, 1973). En este caso, el agente del cambio no es externo sino interno; el cambio del sistema artístico se ejerce desde el propio corazón y a partir del conocimiento de sus reglas y valores ${ }^{7}$.

\subsection{La sociología del arte interaccionista: el mundo artístico, las convenciones, el mercado y las estrategias profesionales como agentes del cambio}

En segundo lugar, en cuanto a la corriente interaccionista se explicará la producción, el consumo y la evaluación de las artes como una forma de acción colectiva. Esta orientación tendrá dos corrientes diferenciadas: la sociología de los mundos del arte de Howard Becker (Becker, 1994; Becker, 2008) y la socioeconomía de los mercados y de las profesiones artísticas desarrollada por Raymonde Moulin (Moulin, 1983; Moulin, 1997; Moulin y Cardinal, 2012). En primer lugar, el sociólogo norteamericano Howard Becker (2008) desarrollará la noción de mundo artístico que se caracterizará, a diferencia de la de campo artístico, por su carácter difuso, basado en convenciones y no explicable en términos de organización formal. Al separarse de la tradición romántica del arte,

\footnotetext{
Aunque algunos autores como Sewell rechazan que verdaderamente Bourdieu haya conseguido superar la dicotomía estructura y agente (Sewell, 1992), el caso del Bourdieu es según Lizardo el intento mejor desarrollado dentro del estructuralismo de concebir la capacidad de agencia (Lizardo, 2010). En este sentido, siguiendo el caso de Édouard Manet, Bourdieu nos presenta el caso de un artista que actúa explotando activamente su capital cultural aprehendido para elaborar soluciones inéditas a aspiraciones que desarrolla y a problemas que encuentra (Bourdieu, 2013). Sin embargo, tal como destaca Roueff, la agencia en el campo artístico solo reconoce la capacidad de agencia muy selectivamente restringiéndola a los "grandes" individuos como Manet (opus cit.), Flaubert (Bourdieu, 2002) o Beethoven (Bourdieu, 2001).

7 Ello lo opone frontalmente a la concepción propia de los cultural studies, en la que la innovación artística proviene de los diferentes, los excluidos, los marginales que, a partir de los contenidos materiales y simbólicos de su vida cotidiana, generan un estilo espectacular (provocador y visible) que rompe con las normas establecidas (Hebdige, 2004). Así, el centro del campo artístico reacciona de forma defensiva al principio, pero al observar el éxito fulgurante y la capacidad de innovación, terminó por cooptar el movimiento y en cierta medida desnaturalizarlo.
} 
este autor destacará el carácter cooperativo de la actividad artística tanto en la esfera productiva (en la que se contemplaría a los autores como ejecutantes y las actividades de apoyo), como en la dimensión de difusión o de creación de marcos generales para esta actividad.

En este caso, el cambio cultural puede generarse simplemente petit à petit de la pura repetición con el surgimiento de pequeñas variaciones en la planificación y la ejecución artística (por ejemplo, el vibratto en la música), o a partir de articulaciones diferentes de la cadena de cooperación artística producidas por los cambios técnicos en los procesos de creación, intermediación o difusión artística. Sin embargo, las llamadas revoluciones artísticas surgirán acompasadas del surgimiento de la figura social del artista, que le otorgará al creador una creciente centralidad y capacidad de coordinación de la cadena cooperativa de trabajo artístico y un mayor control sobre el resultado y uso de su obra. Esta consideración, que sin duda puede ser considerada como un privilegio dentro del campo artístico respecto al resto de agentes cooperadores (técnicos o intermediarios), será la legitimación para que el artista pueda intentar convencer a los agentes del mundo artístico de la bondad de las nuevas formas de creación que puede proponer. Así, estas formas de creatividad no operan en el vacío, sino en el marco de convenciones y profesiones necesarias para el desarrollo de la actividad artística (desde personal de apoyo, ejecutantes, intermediarios y, finalmente pero no menos importante, público). Por ello, para ser exitosas, estas revoluciones artísticas propuestas por los artistas necesitarán la colaboración de parte del mundo artístico (o si no, pueden fracasar y desaparecer en el olvido). Además, los cambios artísticos exigirán desde esta perspectiva la transformación de la cadena de colaboración artística, como es el caso del paso de la canción melódica al rock, en el que los grupos de rock romperán la segmentación del trabajo de las grandes compañías y necesitarán el surgimiento de nuevos intermediarios, como los mánagers y las discográficas independientes (Peterson y Berger, 1996).

Asimismo, los autores no son los únicos en producir cambios, el contexto de recepción y la reacción del público (como la participación del público en el rock de estadio) pueden también generar una transformación en la puesta en escena (luces, efectos de sonido o pantallas) y hasta en la forma de componer, al buscar el eco del público (Becker, 2008). La sociología del arte puede, por lo tanto, estudiar cómo se desarrollan estos procesos de cambio al observar de forma relativista (sin juicos de valor a priori) cómo se producen las modificaciones en el campo creativo y cuáles son los cambios que perduran y los que desaparecen, y cuáles, también, son los agentes activos. En este caso, como podemos observar, la influencia de la estructura social es mucho menos determinista, aunque ejerce una influencia de condicionamiento y facilitación del trabajo artístico (Menger, 1992).

Por otra parte, es de destacar la importancia de la sociología de los mercados y las profesiones y los intermediarios artísticos, que ha sido el origen de toda una escuela de investigaciones empíricas (Jeanpierre y Roueff, 2013) ${ }^{8}$. De este modo,

Este trabajo parte de la sociología del arte francesa de finales del siglo $\mathrm{Xx}$, muy influenciada por Pierre Bourdieu, pero se distancia de ella por una alineación a la corriente más interaccionista y, sobre todo, contraria a la idea de la dominación de la cultura dominante y la homología entre esta y la alta cultura. Uno de sus representantes es Jean-Claude Grignon y especialmente Jean-Claude Passeron, que revindica la relativa autonomía entre cultura y dominación y, especialmente, la posibilidad de desarrollo de un olvido de la dominación y hasta de resistencia cultural en la producción y participación cultural de las clases populares (Grignon y Passeron, 1989). 
esta perspectiva sociológica de raíz interaccionista enfatiza como Bourdieu los condicionantes económicos del arte (lo que en los año sesenta era visto de forma hostil en los sectores culturales y se distanciaba del enfoque humanístico corriente en aquel momento) y su interés en el desinterés (Bourdieu, 1994). Sin embargo, este enfoque se distancia de la teoría bourdiniana en considerar el elemento simbólico como una dimensión del valor cultural y no solo un "truco" en el juego de la distinción social (Becker, 1994). En este sentido, se concentran en construir tipos ideales de empresas, profesionales o estrategias artísticas a partir del estudio de las transformaciones reales de los mercados y profesiones artísticas, sin las consideraciones a priori y la oposición entre subcampos comercial y autónomo, del que parte Bourdieu y del que se quieren distanciar (Moulin, 1983). Por el contrario, estos estudios se centrarán en analizar las trayectorias de los creadores, los acuerdos entre intermediarios y los creadores, y las valoraciones del mercado. Ello les permitirá comprender la evolución artística y los cambios de un paradigma moderno ordenado a partir de fenómenos de alcance medio, contrastables empíricos, como el paso de trayectorias artísticas largas, lentas y cotizaciones estables basadas en la noción de la eternidad del arte a un paradigma posmoderno con trayectorias artísticas cortas y rápidas, y cotizaciones inestables resultado de la idea del tourbillon perpetuel (Moulin, 1997).

Esta corriente de la sociología del arte se concentra en el mercado artístico como agente del cambio, en el que los agentes se comportan como agentes estratégicos para conseguir sus objetivos en un contexto complejo por la naturaleza doble del mundo del arte, como mercancía económica y como producto simbólico (Moulin, 1983; Becker, 1994). Lejos por lo tanto de una racionalidad económica directa, la acción estratégica se enmarca en un sistema de condicionantes (Crozier y Friedberg, 1982), en el que son muy relevantes los intermediarios y su capacidad de conectar artistas, público y coleccionistas para faire le succés del artista. Ello explica que sea tan importante la situación geográfica de la galerías de arte y su concentración en diversos espacios urbanos, que marcan las diferentes etapas del mercado del arte (en París, la Rive droite por el arte tradicional del XIX, la Rive gauche para el arte vanguardista consolidado del siglo Xx y Le Marais para el arte actual emergente), al mismo tiempo que muestran las estrategias de los intermediarios para atraer a los compradores y cerciorarlos de su prestigio, al situarse en los barrios de galerías emergentes (Rius, 2012). En este sentido, el análisis del mapa de galerías nos proporciona un indicador clave en black box del cambio artístico: la estabilidad del mapa urbano de galerías el siglo XIX mostraría una estabilidad o estancamiento del mercado artístico, mientras que los repetidos cambios del mercado neoyorquino serían un síntoma de su fulgurante dinamismo basado en el fenómeno de los barrios artísticos (Moulin, 1997; Rius-Ulldemolins, 2016).

\subsection{La corriente institucionalista del cambio social: el cambio artístico impulsado por los cambios técnicos y la organización de la producción cultural}

La corriente institucionalista de la sociología de las artes parte del trabajo desarrollado por la sociología de la ciencia impulsada por Merton $(1984,1996)$. Se trata de una sociología de medio alcance aplicada al análisis del desarrollo de la 
esfera social dedicada a generar el conocimiento científico certificado y regulada por instituciones, normas, patrones de carrera y un ethos particular. Esta aplicación de la perspectiva de la sociología de la ciencia a la sociología de las artes viene de la mano de dos sociólogas norteamericanas. En primer lugar, Diana Crane aplica sus estudios sobre la organización de la innovación (Crane, 1972) a su estudio de la creatividad y la innovación cultural en las vanguardias de Nueva york (Crane, 1976). En segundo lugar es Remi Clignet quien investiga las semejanzas y diferencias de las revoluciones científicas teorizadas por Kuhn (2006) y las revoluciones artísticas (Clignet, 1985). Asimismo, esta línea de trabajo - que parte de la sociología de la ciencia, y que combina la idea de esfera autodefinida y la noción de conflicto de Weber con las aportaciones durkhemianas de los rituales de interacción simbólica - es también adoptada y desarrollada de forma brillante por Randall Collins en su concepción del cambio cultural en el pensamiento (Collins, 1989). Para este autor, es la interacción (colaborativa y competitiva), su difusión en una red especializada y posterior "efecto halo" los que explican el éxito y la pervivencia de símbolos, y no los factores del genio individual ni tampoco de la estructura social externa (Collins y Guillen, 2012). Unas nociones que sin duda son seductoras, pero que tienen dificultades para ser operacionalizadas en la explicación del cambio en esferas artísticas específicas. Sin embargo, más característico de la perspectiva institucionalista es el trabajo Careers and Creativity: Social Forces in the Arts, desarrollado por Harrison C. White (1993). En él se muestra cómo el cambio del arte académico al arte impresionista no es producido por una lógica puramente estética, sino que detrás de este cambio de paradigma artístico se encuentra una sustitución del sistema institucional del arte: el paso del sistema académico al sistema del mercado artístico.

Pero sin duda, uno de los modelos más influyentes a finales del siglo XX para explicar el cambio artístico ha sido el paradigma de la producción de la cultura de Richard Peterson (Peterson y Anand, 2004). La aportación principal de la perspectiva de Peterson (op. cit.) es explicar el cambio de los sistemas simbólicos, en el que podemos incluir las artes, la cultura popular o los sistemas de generación de conocimiento, en función de las variaciones en la organización social de su producción, distribución y usos. De este modo, Peterson propone un modelo de siete facetas para explicar el cambio artístico: regulaciones legales, tecnología, estructura de la industria, estructura de la organización, carreras ocupacionales y condiciones del mercado (Peterson, 1982). Su intención es señalar: "Hay una asociación clara entre la naturaleza de la industria y los mensajes contenidos en las canciones, y el cambio en lo primero precede los cambios en los últimos (...). Esto nos lleva a concluir que las inesperadas canciones de rock en los años sesenta (y la contracultura que creó) estaban en gran medida generando unos efectos inesperados de los cambios profundos acaecidos en la tecnología, la estructura de la industria y el marketing" (Peterson y Berger, 1972: 283; traducción del autor). Por ello, una de sus aplicaciones más interesantes es su artículo en el que responde por qué la música rock surge en 1955 (Peterson, 1990). Las repuestas habituales a esta cuestión hacen referencia a la aparición de nuevos artistas o al surgimiento de una ola creativa en la música popular. Por el contrario, Peterson, siguiendo el método durkhemiano, desmonta estos argumentos uno por uno al mostrar que ya existían corrientes creativas anteriormente similares al rock and roll, pero que había 
factores institucionales que frenaban e impedían lo que después sería una de las corrientes creativas más significativas en la segunda mitad del siglo XX.

De este modo, Peterson muestra cómo es la combinación de: A) Modificaciones regulativas (liberalización de las licencias de radio). B) Innovaciones tecnológicas como el disco de vinilo y la combinación de estos dos factores, entre otros, que permite a las discográficas pequeñas enviar sus discos más innovadores a las radios locales. Ello permite el surgimiento del rock y la transformación paralela de cambios organizativos (el surgimiento del grupo de rock que compone e interpreta). C) El cambio organizativo de las empresas, con el surgimiento de nuevos emprendedores y técnicos independientes vinculados a los nuevos estilos (promotores musicales, técnicos de sonido, etc.). D) Transformación de la industria musical independiente, que hunde el control oligopólico de las majors e inaugura un largo periodo de treinta años de gran competencia y gran innovación (ibidem). Se trata por lo tanto de una middle range-theory multifactorial (DiMaggio, 2000) que abandona los planteamientos holísticos y deterministas, y por el contrario moviliza la sociología del trabajo (la esfera de la producción y los incentivos de las carreras), la sociología de las organizaciones (para comprender las relaciones de autoridad, de gestión de la información y de relación entre organizaciones) y de las industrias (y de la influencia del mercado y del grado de competencia). Asimismo, esta perspectiva será aplicada a las industrias culturales con éxito y, al mismo tiempo, será aplicada por DiMaggio al estudio del surgimiento del sistema de instituciones non for profit de la alta cultura en EE. UU. y su relación con el surgimiento de una clase media alta cultivada (DiMaggio, 1987).

Si bien algunos autores han criticado de esta perspectiva la ausencia de análisis en profundidad del objeto cultural en sí y de su contenido, ciertamente la perspectiva de la producción de la cultura de Peterson se ha convertido en un paradigma central en la sociología de las artes (DiMaggio, 2000). Sin embargo, uno de sus puntos ciegos ha sido el de dejar en un segundo plano la importancia de la acción cultural pública, útil especialmente en relación a las esferas de producción industriales (música, cine y, en menor medida, artes escénicas), y no tanto en las esferas más artesanales y en aquellas que permiten la autoproducción DIY, el amateurismo o las prácticas culturales. Un déficit explicativo que el mismo Peterson intentó subsanar con el desarrollo de un marco interpretativo y de investigación de las dos lógicas de la producción cultural, en la que aparte de la lógica industrial ya comentada, existe una lógica de autoproducción en la que los individuos y los grupos adoptan símbolos y, al recombinarlos, hacen de ellos una forma de identidad (Peterson, 2000). Con ello responde a la crítica que se le hacía desde los cultural studies y su idea del cambio cultural desde la periferia social. Ha ganado una creciente dimensión con las posibilidades abiertas a los amateurs por las nuevas tecnologías de la información y la comunicación, que facilitan el trabajo creativo y lo aproximan en calidad a la producción profesional (Jenkins, 2009). Finalmente, en general debemos destacar este paradigma como una aportación valiosa a la concepción del cambio artístico y su contexto social, pero sobre todo es relevante y perdurable porque permite un trabajo empírico y comparativo procedente de diversos campos culturales desde la perspectiva sociológica (Santoro, 2008). 


\section{La perspectiva posmoderna del cambio artístico centrada en el espacio: el retorno de la perspectiva macro y sus sobreinterpretaciones}

En el desarrollo de la sociología de las artes como disciplina, se ha reconocido de forma cada vez más abierta una autonomía al cambio artístico respecto al cambio social. Sin embargo, en los años noventa podemos observar un retorno de las teorías macro sociológicas y heteronomistas aplicadas al cambio cultural, desde una perspectiva neomarxista o neoweberiana, que se dirigen a analizar los cambios acontecidos en las sociedades desarrolladas a partir de los años setenta. Desde este punto de vista, los cambios en la esfera de la economía, trabajo y el consumo, el proceso de desregulación y desorganización producen la fragmentación y la orientación hacia la identidad y lo estético en las sociedades avanzadas (Lash, 1997; Lash y Urry, 1998). Así, estos cambios son interpretados como la base infraestructural del cambio artístico, que genera una producción artística desestructurada y fragmentada, y son el collage, el mix y el mush up los símbolos de esta fragmentación (Anderson, 1998; Harvey, 1998). Además, otra vez encontramos una interpretación macro de los cambios en la esfera artística, pero esta vez se introduce una intencionalidad en los cambios culturales, que son los de legitimar la recomposición del capitalismo y los procesos de revalorización urbana y su gentrificación (Harvey, 2005). Esta es una explicación que a veces ha llegado a situar el sector artístico como cómplice necesario de estos procesos (Deutsche y Gendel Ryan, 1984; Lloyd, 2002), lo que nos parece una sobredeterminación cercana a la lógica althuseriana de convertir todo lo cultural en aparatos ideológicos del Estado capitalista (Althusser, 1974).

En todo caso, en los años ochenta se han desarrollado unas teorías posmodernas (o en reacción a esta orientación) que podemos calificar de culturalistas. Estas imponen la idea posmoderna de la desestructuración y desclasificación de las oposiciones entre arte comercial y arte puro, entre arte de vanguardia y arte burgués, característica de la modernidad y sus estructuras sociales, políticas y estéticas (Menger, 2016). Una dinámica que tiene su expresión en una crisis de la lógica artística moderna basada en la lógica universal de la innovación, y en la decadencia del modelo de vanguardia artística internacional (Crane, 1987). Esta crisis de la dimensión temporal en la explicación de la lógica histórica conlleva para algunos autores el resurgimiento del factor espacial (Jameson, 1991). Para algunos autores, esta nueva etapa se deshace de los encorsetamientos de las lógicas modernas y abre un mundo de posibilidades a partir de la fragmentación, la deconstrucción, la mezcla, el collage o el simulacro más allá de las fronteras y las especializaciones de la sociedad moderna, lo que genera una lógica de circulación de flujos, estilo y objetos artísticos a nivel mundial sin las barreras de niveles artísticos o fronteras entre sectores artísticos (Lash, 1990; Rodríguez Morató, 2007). El ejemplo más celebrado en este sentido es el surgimiento de corrientes artísticas transdisciplinares que, como en la Factory de Andy Warhol, mezclan artistas y lenguajes conformando laboratorios de innovación (Currid, 2007). En este contexto gana importancia el aspecto, el estilo de la fachada de los edificios así como el diseño de los productos que se enraíza en la 
construcción de una imagen de sitio, como es el caso del estilo de Los Ángeles (Molotch, 1996; Molotch, 2002).

Por otra parte, si la autonomía de la esfera artística señala el punto culminante de la modernidad entendida como el desarrollo máximo de una lógica autorreferente (Bourdieu, 2002), la crisis de esta etapa histórica y la entrada de dinámicas posmodernas implica todo lo contrario, el proceso de desdiferenciación de esferas y la mezcla de lógicas externas a la propia esfera social, o su heteronomización (Bourdieu, 1997). Así, Scott Lash afirma que este proceso ya no se puede comprender con el paradigma weberiano, sino bajo el prisma de Walter Benjamin (Lash, 1997), en el que se producen cuatro transformaciones en el paradigma cultural: 1) La relación entre los tipos de objetos culturales producidos, por ejemplo, estético, teórico, ético. 2) La relación entre lo cultural como conjunto y lo social. 3) La economía cultural: las condiciones de producción y consumo, las instituciones de la cultura, el modo de circulación y el producto cultural. Y 4) El modo de significación, las relaciones entre significante, significado y referente. Por ello, si la modernidad presuponía la diferenciación de estas unidades, la posmodernización se desarrolla a partir de la desdiferenciación de estos cuatro componentes: mezcla de objetos culturales y discursos, mayor promiscuidad entre arte y usos sociales, hibridación de la economía cultural entre niveles y formas culturales y una mezcla entre los modos de significación y una crisis de la noción de obra y

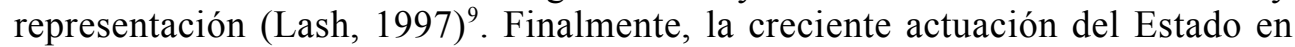
la esfera pública ha generado una progresiva dependencia de los recursos públicos, que los hace más permeables a las orientaciones de la política cultural e instrumentalizaciones para objetivos sociales o económicos (Gray, 2008).

Sin embargo, en los contextos desarrollados por la orientación posmoderna de la sociología de la cultura, el elemento propiamente artístico aparece desdibujado, sin referencia sistemática a los procesos de producción cultural y sin conexión con la generación de nuevos estilos, aparte de la mezcla o la repetición viral de contenidos culturales (Pecourt Gracia y Rius-Ulldemolins, 2018). Como en los desarrollos de la sociología del arte anterior a su desarrollo moderno en los años setenta, el paso del contexto social al estilo artístico aparece como un black box sin operacionalización ni mecanismos causales o interpretativos de cómo, cuándo y de qué manera operan más allá de una vaga noción de contexto, frame o ritual sin conexión con un caso concreto singular y real. En este sentido, es difícil diferenciar las interpretaciones posmodernas centradas en el espacio y no en el sector y su organización de los simples trucos del marketing del branding urbano $^{10}$. De mayor rendimiento analítico son los análisis cuantitativos y

$9 \quad$ En esta línea, debemos enmarcar el trabajo de Arturo Rodríguez, que propone adaptar esta orientación posmoderna a la sociología del arte anterior con su concepto de la sociedad de la cultura, postulando la nueva centralidad de la cultura en las sociedades avanzadas. Así, parafraseando críticamente a Bourdieu, postula la aparición de unas "nuevas reglas del arte" en las que impera la dinámica de autonomización y la separación de la esfera artística respecto a las otras esferas sociales (especialmente la económica pero también la política). Según esta visión, las oposiciones entre arte comercial y arte puro y entre las nuevas y viejas vanguardias configuradas en el nivel nacional habrían dejado de ser el elemento fundamental, para desarrollarse una nuevas dinámicas creativas centradas en la cultura local, en la que elementos sociales, culturales y artísticos locales se combinarían de forma sincrética (Rodríguez Morató, 2007).

10 Una muestra de este branding ha sido la creación de la marca Barcelona, muy exitosa en su promoción turística, pero de rendimiento mucho menor en su proyección de los artistas y los sectores culturales (Zamorano y Rodríguez Morató, 2015). 
cualitativos de las redes y los espacios de consagración realizados por Alain Quemin. En ellos aparecen los espacios conectados a las redes globales de los sectores artísticos, como las ferias de arte o festivales culturales, que configuran actualmente los canales en los que se genera y vehicula la innovación cultural actualmente (Quemin, 2013). Finalmente, los casos privilegiados de estudio de esta corriente posmoderna: las fábricas de creación, fablabs o estudios artísticos, más que escenarios de creación y experimentación, más que por su producción cultural, son conocidos como escenarios de sociabilidad y consumo hipster. En ellos, en lugar de Polanyi y su lógica de reciprocidad característica de las redes artísticas, prevalece Bourdieu y las lógicas distintivas de estatus (Scott, 2017).

\section{Comentarios finales}

La relación del cambio social sobre el cambio artístico ha sido interpretada durante el siglo XIX y buena parte del siglo XX a partir de una idea organicista $\mathrm{O}$ determinista, en la que el arte era expresión o reflejo del progreso, la civilización o las clases sociales. Estos enfoques han sido interesantes como aproximaciones macrosociológicas, pero solamente permiten generalizaciones y comparaciones extremadamente genéricas, y son muy poco significativos en lo que se refiere a las evoluciones contemporáneas de las artes. Así, otras corrientes como el funcionalismo, el marxismo o el estructuralismo (y en ciertas lecturas muy centradas en la etnia o las identidades de los cultural studies) han sido excesivamente deterministas sobre el arte en relación a sus condiciones sociales.

Por el contrario, el perfeccionamiento de la sociología de las artes contemporáneas ha comportado la elaboración de teorías de medio alcance y herramientas heurísticas que contemplan la autonomía de la esfera artística, como la teoría de los campos de Bourdieu (y su idea de los subcampos y oposiciones conflictivas sobre el capital simbólico), los mundos del arte (y sus conceptos de cooperación, convención, interacción) o la perspectiva institucionalista (con su enfoque multidimensional de las facetas y la influencia del trabajo, la organización y el mercado). Por último, una vez más las interpretaciones posmodernas de la creatividad acaban disolviéndose en olas de escenarios de consumo y de recreación de estilos de vida más que de análisis concretos de cómo los artistas generan valor cultural en un contexto específico, con unos materiales simbólicos y unas redes sociales y profesionales que, a pesar de la lógica posmoderna de mezcla, siguen siendo esferas culturales autónomas altamente elitistas y conectadas internacionalmente (Moulin y Cardinal, 2012). Finalmente, a diferencia de la orientación posmoderna en la sociología de las artes sobre la cultura, las orientaciones estructural, interaccionista $o$ institucional han aportado herramientas útiles para desencriptar la black box de la relación entre cambio social y cambio artístico y su análisis empírico en los mundos artísticos. 
Tabla 1. Énfasis principal e influencia de la estructura en la explicación del cambio artístico respecto al cambio social en la sociología de las artes

\begin{tabular}{|c|c|c|c|}
\hline & & \multicolumn{2}{|l|}{ Énfasis principal } \\
\hline & & $\begin{array}{l}\text { Heteronomía, } \\
\text { sociedad y arte }\end{array}$ & $\begin{array}{l}\text { Autonomía, } \\
\text { sociedad y arte }\end{array}$ \\
\hline \multirow{3}{*}{$\begin{array}{l}\text { Influencia } \\
\text { atribuida } \\
\text { a la } \\
\text { estructura }\end{array}$} & $\begin{array}{l}\text { Casi } \\
\text { inexistente }\end{array}$ & $\begin{array}{l}1 \\
\text { Teoría de las civilizaciones } \\
\text { Cultural Studies } \\
\text { (culturalistas) }\end{array}$ & $\begin{array}{l}2 \\
\text { Interaccionismo } \\
\text { simbólico: Howard Becker } \\
\text { Teorías posmodernas } \\
\text { culturalistas }\end{array}$ \\
\hline & Contingente & $\begin{array}{l}3 \\
\text { Pierre Bourdieu, consumo } \\
\text { cultural } \\
\text { Cultural Studies } \\
\text { (gramscianos o foucaltianos) }\end{array}$ & $\begin{array}{l}4 \\
\text { Max Weber } \\
\text { Marxismo agencialista } \\
\text { Sociología francesa, } \\
\text { profesiones artísticos } \\
\text { Pierre Bourdieu, } \\
\text { producción cultural }\end{array}$ \\
\hline & $\begin{array}{l}\text { Casi } \\
\text { absoluta }\end{array}$ & $\begin{array}{l}5 \\
\text { Marxismo estructuralista } \\
\text { Estructuralismo } \\
\text { Estructural funcionalismo } \\
\text { (corriente principal) }\end{array}$ & $\begin{array}{l}6 \\
\text { Teorías posmodernas } \\
\text { neomarxistas }\end{array}$ \\
\hline
\end{tabular}

Fuente: elaboración propia.

\section{Bibliografía}

Althusser, L. (1974): Ideología y aparatos ideológicos del Estado, Buenos Aires, Nueva Visión.

Anderson, P. (1998): Los orígenes de la posmodernidad, Barcelona, Anagrama.

Becker, H. (1994): "La confusion des valeurs", en P. Menger y J. Passeron, eds, .L'art de la recherche, Essais en l'honneur de Raymonde Moulin, Paris, La Documentation française, pp. 24-39.

Becker, H. S. (2008): Los mundos del arte. Sociología del trabajo artístico, Buenos Aires, Universidad Nacional de Quilmes.

Boltanski, L. y E. Chiapello (2002): El nuevo espíritu del capitalismo, Madrid, Akal.

Bourdieu, P. (1994): Raison pratiques: sur la théorie de l'action, Paris, Seuil.

Bourdieu, P. (1997): Sobre la televisión, Barcelona, Anagrama.

Bourdieu, P. (1977): "La production de la croyance : contribution à une économie des biens symboliques", Actes de la recherche en sciences sociales, 13, pp. 3-43.

Bourdieu, P. (1997): "De la maison du roi à la raison d'État. Un modèle de la genèse du champ bureaucratique ", Actes de la recherche en sciences sociales, 118, pp. 55-68. 
Bourdieu, P. (2001): "Bref impromptu sur Beethoven, artiste entrepreneur", Sociétés \& Représentations, 1, pp. 13-18.

Bourdieu, P. (2002): Las Reglas del arte: génesis y estructura del campo literario, Barcelona, Anagrama.

Bourdieu, P. (2002): Las reglas del arte: génesis y estructura del campo literario, Barcelona, Anagrama.

Bourdieu, P. (2008): Homo academicus, Madrid, Siglo XXI.

Bourdieu, P. (2013): Manet, une révolution symbolique. Cours au Collège de France (1998-2000) suivis d'un manuscrit inachevé de Pierre et Marie-Claire Bourdieu, Paris, Seuil.

Çaksu Ali (2017): "Ibn Khaldun and Philosophy: Causality in History", Journal of Historical Sociology, 30, pp. 27-42.

Casanova, P. (2001): La república mundial de las letras, Barcelona, Anagrama.

Clignet, R. (1985): The Structure of Artistic Revolutions, Philadelphia, Univ of Pennsylvania Press.

Collins, R. (1987): Weberian sociological theory, digital repr edn, Cambridge etc., Cambridge University Press.

Collins, R. (1989): "Toward a Theory of Intellectual Change: The Social Causes of Philosophies", Science, Technology, \& Human Values, 14, pp. 107-140.

Collins, R. y M. F. Guillen (2012): "Mutual halo effects in cultural production: the case of modernist architecture", Theory and Society, 41, pp. 527-556.

Coulangeon, P. y J. Duval (2013): Trente ans après La Distinction, de Pierre Bourdieu. Paris: La Découverte.

Crane, D. (1972): Invisible colleges. Diffusion of knowledge in scientific communities, Chicago, The University of Chicago Press.

Crane, D. (1976): "Reward Systems in Art, Science, and Religion", American Behavioral Scientist, 19, pp. 719-734.

Crane, D. (1987): The transformation of the Avant-Garde: the New York Art World, 1940-1985, Chicago, The University of Chicago Press.

Crozier, M. y E. Friedberg (1982): L'Acteur et le système: les contraintes de l'action collective, Paris, Éditions du Seuil.

Currid, E. (2007): The Warhol economy: how fashion, art, and music drive New York City, Princeton University Press.

Deutsche, R. y C. Gendel Ryan (1984): "The Fine Art of Gentrification", October, 31, pp. 91-111.

DiMaggio, P. (1987): "Nonprofit Organizations in the Production and Distribution of Culture", en W. W. Powell, ed.The Nonprofit Sector: A Research Handbook, New Haven, Yale University Press, pp. 195-220.

DiMaggio, P. (2000): "The production of the scientific change. Richard Peterson and the institutional turn in cultural sociology", Poetics, 28, pp. 136.

Dubois, V. (1999): La politique culturelle. Genèse d'une catégorie d'intervention publique, Paris, Belin.

Eisenstadt, S. N. (1973): "El carisma, la creación de instituciones y la transformación social", Revista de Estudios Políticos, 187, pp. 65-112.

Furió, V. (2000): Sociología del arte, Madrid, Cátedra.

Giddens, A. (1994): El capitalismo y la moderna teoría social, Barcelona, Labor. 
Gouldner, A. W. y N. Míguez (1979): La crisis de la sociología occidental, Buenos Aires, Amorrortu.

Granovetter, M. (1979): "The Idea of "Advancement", in "Theories of Social Evolution and Development", American Journal of Sociology, 85, pp. 489-515.

Gray, C. (2008): "Instrumental policies: causes, consequences, museums and galleries", Cultural Trends, 17, pp. 209-222.

Grignon, C. y Passeron, J. (1989): Le savant et le populaire: misérabilisme et populisme en sociologie et en littérature, Paris, Gallimard : Seuil.

Hall, S. (1992): Culture, media, language :working papers in cultural studies, 1972-79, London, Routledge.

Harvey, D. (1998): La condición de la posmodernidad. Investigación sobre los orígenes del cambio cultural, Buenos Aires, Amorrortu.

Harvey, D. (2005): "El arte de la renta: la globalización y la mercantilización de la cultura", en D. Harvey y N. Smith, eds. Capital financiero, propiedad inmobiliaria y cultura, Barcelona, Museu d'Art Contemporani de Barcelona, pp. 29-58.

Hebdige, D. (2004): Subcultura: el significado del estilo, Barcelona, Paidós.

Heinich, N. (1983): "La perspective académique. Peinture et tradition lettrée : la référence aux mathématiques dans les théories de l'art au 17ème siècle", Actes de la recherche en sciences sociales, 49, pp. 47-70.

Heinich, N. (1990): "Académisation et provincialisation des carrières de peintres en Provence au XVIIe siècle", Annales. Économies, Sociétés, Civilisations, 45, pp. 1301-1315.

Heinich, N. (1998): Ce que l'art fait à la sociologie, Paris, Éditions de Minuit.

Heinich, N. (2001): La sociologie de l'art, Paris, Éd. La Découverte.

Hennion, A. (2004): "Une sociologie des attachements. D'une sociologie de la culture à una pragmatique de l'amateur", Sociétés, 85, pp. 9-24.

Jameson, F. (1991): El posmodernismo o la lógica cultural del capitalismo avanzado, Madrid, Paidos.

Jeanpierre, L. y O. Roueff (2013): La culture et ses intermédiaires. Dans les arts, le numérique et les industries créatives, Strasbourg, Éditions des archives contemporaines.

Jenkins, H. (2009): Fans, blogueros y videojuegos: la cultura de la colaboración, Barcelona, Paidós.

Kavolis, V. (1965): "Art Content and Economic Reality", American Journal of Economics and Sociology, 24, pp. 321-329.

Kavolis, V. (1966): "Community Dynamics and Artistic Creativity", American Sociological Review, 31, pp. 208-217.

Kuhn, T. S. (2006): La estructura de las revoluciones cientificas, México, Fondo de Cultura Económica.

Lash, S. (1990): Sociology of Postmodernism, London, Routledge.

Lash, S. (1997): Sociología del posmodernismo, Buenos Aires, Amorrortu.

Lash, S. y J. Urry (1998): Economías de signos y espacio: Sobre el capitalismo de la posorganización, Buenos Aires, Amorrortu.

Lizardo, O. (2004): "The Cognitive Origins of Bourdieu's Habitus", Journal for the Theory of Social Behaviour, 34, pp. 375-401.

Lizardo, O. (2010): "Beyond the antinomies of structure: Levi-Strauss, Giddens, Bourdieu, and Sewell", Theory and Society, 39, pp. 651-688. 
Lloyd, R. (2002): "Neo-Bohemia: Art and Neighborhood Redevelopment in Chicago", Journal of Urban Affairs, 24, pp. 517-532.

Lukács, G. (1975): Historia y consciencia de clase, Barcelona, Grijalbo.

Menger, P. (1992): "Les paradigmes de la sociologie de l'art", en I. Domínguez y A. Rodríguez, eds., Arte, cultura y Sociedad, Bilbao, AESCA, pp. 42-57.

Menger, P. (2009): Le travail créateur. S'accomplir dans l'incertain, Paris, Gallimard.

Menger, P. (2011): "Les politiques culturelles. Modeles et évolutions", en P. Poirrier, ed. Pour une histoire des politiques culturelles dans le monde (1945-2011), Paris, La Documentation française, pp. 465-479.

Menger, P. (2016): "Art, politització i acció pública", Debats. Revista de cultura, poder $i$ societat, 130 (2), pp.73-94.

Merton, R. K. (1984): Ciencia, tecnología y sociedad en la Inglaterra del siglo XVII, Madrid, Alianza.

Merton, R. K. (1996): On Social Structure and Science, Chicago, The University of Chicago Press.

Molotch, H. (1996): "L.A. as a Design Product: How Arts Works in a Regional Economy", en A. J. Scott y E. W. Soja, eds. The City: Los Angeles and Urban Theory at the End of the Twentieth Century, Los Angeles, University of California Press, pp. 225-275.

Molotch, H. (2002): "Place in product", International Journal of Urban and Regional Research, 26, pp. 665-688.

Moulin, R. (1983): Le marché de l'art en France, Paris, Éditions de Minuit.

Moulin, R. (1997): L'Artiste, l'institution et le marché, Paris, Flammarion.

Moulin, R. y M. Cardinal (2012): El mercado del arte: mundialización y nuevas tecnologías, Buenos Aires, La Marca.

Nisbet, R. y T. S. Kuhn (1993): Cambio social, Madrid, Alianza Universidad.

Oakes, G. (2003): "Max Weber on Value Rationality and Value Spheres: Critical Remarks", Journal of Classical Sociology, 3, pp. 27-45.

Pareto, V. y R. Aron (1968): Traité de sociologie générale, Genève, Droz.

Passeron, J. C. (2011): El razonamiento sociológico :el espacio comparativo de las pruebas históricas, Madrid, Siglo XXI.

Pecourt Gracia, J. y J. Rius-Ulldemolins (2018): "La digitalización del campo cultural y los intermediarios culturales: una crítica social del utopismo digital", Revista Española de Investigaciones Sociológicas, 162, pp. 73-90.

Peterson, R. A. (1982): "Five Constraints on the Production of Culture: Law, Technology, Market, Organizational Structure and Occupational Careers*", The Journal of Popular Culture, 16, pp. 143-153.

Peterson, R. A. (1990): "Why 1955? Explaining the Advent of Rock Music", Popular Music, 9, pp. 97-116.

Peterson, R.A. 2000: Two ways culture is produced.

Peterson, R. A. y D. G. Berger (1972): "Three eras in the manufacture of popular lyrics", en R. S. Denisoff, ed. Sounds of social chance, Nueva York, Rand Mac Nally, pp. 282-303.

Peterson, R. A. y D. G. Berger (1996): "Measuring Industry Concentration, Diversity and Innovation in Popular Music", American Sociological Review, 61, pp. 175-178.

Peterson, R. A. y N. Anand (2004): "The production of culture perspective", Annu. Rev. Sociol, 30, pp. 311-334.

Pinto, L., G. Sapiro, P. Champagne y M. Rivière (2004): Pierre Bourdieu, sociologue, Paris, Fayard. 
Quemin, A. (2013): "International Contemporary Art Fairs in a 'Globalized' Art Market", European Societies, Volume 15, pp. 162-177.

Ritzer, G. (1997): Postmodern social theory, New York, McGraw-Hill.

Rius, J. (2012): "Gallery Districts of Barcelona: The Strategic Play of Art Dealers", The Journal of Arts Management, Law and Society, 42, pp. 48-62.

Rius-Ulldemolins, J. (2016): ¿¿Por qué las galerías de arte se concentran en clústeres? Un análisis sociológico de la estructura y dinámica urbana del mercado del arte", Revista Española de Sociología, 25, pp. 205-225.

Rodríguez Morató, A. (2007): "La perspectiva de la sociedad de la cultura", en La sociedad de la cultura, Barcelona, Ariel, pp. 11-51.

Rosenberg, H. (1959): The tradition of the new, New York, Horizon Press.

Santoro, M. (2008): "Culture As (And After) Production", Cultural Sociology, 2, pp. 7-31.

Sapiro, G. (1996): "La raison littéraire. Le champ littéraire français sous l'Occupation (1940-1944)", Actes de la recherche en sciences sociales, 111, pp. 3-35.

Sapiro, G. (2013). Le champ est-il national ? [Is the Field National?] Actes de la recherche en sciences sociales, 200(5), 70-85. doi:10.3917/arss.200.0070.

Sapiro, G. (2017): "Sobre l'ús de les categories de 'dreta' i 'esquerra' en el camp literari", Debats. Revista de cultura, poder i societat, 130, pp. 99-124.

Scott, M. (2017): "'Hipster Capitalism' in the Age of Austerity? Polanyi Meets Bourdieu's New Petite Bourgeoisie", Cultural Sociology, 11, pp. 60-76.

Sewell, W. H. (1992): "A Theory of Transformation: Duality, Agency and Transformation", American Journal of Sociology, 98 (1), pp. 1-29.

Sorel, G. (1947): Les illusions du progrès, Paris, Librairie Marcel Rivière.

Sorokin, P. A. (1937): Social and Cultural Dynamics: Vol. I: Fluctuation of Forms of Art. Vol. II: Fluctuation of Systems of Truth, Ethics, and Law. Vol. III: Fluctuation of Social Relationships, War, and Revolution, New York, American Book.

Sorokin, P. A. (1966): Las filosofías sociales de nuestra época de crisis: el hombre frente a la crisis: Danilevsky, Spengler, Toynbee, Schubart, Berdiaeff, Northrop, Kroeber, Schweitzer, Madrid, Aguilar.

Spengler, O. (1966): La decadencia de Occidente: bosquejo de una morfología de la Historia Universal: Tomo 1, Madrid, Espasa-Calpe.

Tilly, C. (1991): Grandes estructuras, procesos amplios, comparaciones enormes, Madrid, Alianza Editorial.

Toynbee, A. (1970): Estudio de la Historia, Madrid, Alianza.

Weber, M. (1944): Economía y Sociedad, México, Fondo de Cultura Económica.

White, H. C. (1993): Careers and creativity: social forces in the arts, Colorado, Westview Press.

White, H. C. y C. A. White (1991): La Carrière des peintres au XIXe siècle: du système académique au marché des impressionnistes, Paris, Flammarion.

Williams, R. (1994): Sociología de la cultura, Barcelona, Paidós.

Williams, R. (1997): Marxismo y literatura, Barcelona, Península.

Zamorano, M. M. y A. Rodríguez Morató (2015): "The cultural paradiplomacy of Barcelona since the 1980s: understanding transformations in local cultural paradiplomacy", International Journal of Cultural Policy, 21, pp. 554-576.

Zolberg, V. L. (2016): Sociología de las artes, Madrid, Fundación Autor. 